\title{
Predicting metabolism during growth by osmotic cell expansion
}

Sanu Shameer ${ }^{1}$, José G. Vallarino ${ }^{2}$, Alisdair R. Fernie ${ }^{2}$, R. George Ratcliffe ${ }^{1}$, Lee J Sweetlove ${ }^{1}$

${ }^{1}$ Department of Plant Sciences, University of Oxford, Oxford, UK

${ }^{2}$ Max Planck Institute for Molecular Plant Physiology, Potsdam-Golm, Germany

\begin{abstract}
Cell expansion is a significant contributor to organ growth and is driven by the accumulation of osmolytes to increase cell turgor pressure. Metabolic modelling has the potential to provide insights into the processes that underpin osmolyte synthesis and transport, but the main computational approach for predicting metabolic network fluxes, flux balance analysis (FBA), typically uses biomass composition as the main output constraint and ignores potential changes in cell volume. Here we present GrOE-FBA (Growth by Osmotic Expansion- Flux Balance Analysis), a framework that accounts for both the metabolic and ionic contributions to the osmotica that drive cell expansion, as well as the synthesis of protein, cell wall and cell membrane components required for cell enlargement. Using GrOE-FBA, the metabolic fluxes in dividing and expanding cell were analyzed, and the energetic costs for metabolite biosynthesis and accumulation in the two scenarios were found to be surprisingly similar. The expansion phase of tomato fruit growth was also modelled using a multi-phase single optimization GrOE-FBA model and this approach gave accurate predictions of the major metabolite levels throughout fruit development as well as revealing a role for transitory starch accumulation in ensuring optimal fruit development.
\end{abstract}

\section{INTRODUCTION}

Flux balance analysis (FBA), a method for predicting and analysing steady-state metabolic fluxes, has been widely applied in the study of unicellular and multicellular plant systems (Sweetlove and Ratcliffe, 2011; Nikoloski et al., 2015; de Oliveira Dal'Molin and Nielsen, 2018). The approach requires a matrix of metabolic reaction stoichiometries and an objective function that represents the optimisation target of the biological system (Feist and Palsson, 2010). In simple unicellular organisms growing in a nutrient-rich environment, where life cycle events involve only growth and reproduction, the maximization of flux representing the accumulation of biomass elements has proved to be a reasonable objective function (Varma and Palsson, 1994; Feist et al., 2007; Feist and Palsson, 2010). In complex biological systems, however, accumulation of biomass may not be the primary purpose of every cell type in the organism. For example, the principal metabolic objective of fully expanded source leaves is the biosynthesis of sucrose and amino acids for the rest of the plant (Cheung et al., 2014). Moreover, organ development in plants typically involves phases of cell differentiation, cell division and cell expansion (Gonzalez et al., 2012) and these are not temporally synchronous, meaning that at different stages of organ development different mechanisms of growth are dominant. Metabolism, being closely related 
to the demands of the cell, is thus likely to vary between these stages of development (Sweetlove and Ratcliffe, 2011; Nikoloski et al., 2015). The cell expansion stage is responsible for the main increase in organ size and metabolic content in plants, and it is the dominant mechanism when growth is measured during plant phenotyping (Fahlgren et al., 2015; Tardieu et al., 2017). This makes understanding metabolism in expanding cells of great interest and relevance to breeding and crop engineering. In its conventional form FBA does not take account of the changing volume of the cell, indicating the need for a new FBA formulation if this objective is to be achieved.

To provide a biological context, we focused on tomato, Solanum lycopersicum, which has an extensive phase of cell expansion during fruit development. This process has been described in detail at the molecular-biochemical level (Valle et al., 1998; Carrari and Fernie, 2006; Carrari et al., 2006; Legland et al., 2012; Biais et al., 2014) and the available biochemical data can be used to guide the new FBA formulation. Tomato is also an important model for fleshy fruit development and ripening, owing to its agronomic value, ease of cultivation and diploid genetics. FBA has been previously used to model steady-state snapshots of tomato fruit metabolism at different stages of development (Colombié et al., 2015). This was achieved by using time-series metabolomic datasets to constrain metabolite accumulation and degradation rates in a model of primary metabolism. This snapshot approach is informative, but it has three disadvantages. First, accurate predictions of metabolic state, including the accumulation of solutes during cell expansion, can only be made by imposing a large number of experimentally measured constraints. Secondly, the majority of the flux predictions are a direct consequence of the constraints imposed. For example, the rate of starch degradation observed in the model was the result of a constraint that dictates that starch is consumed at a set rate. Thirdly, because each developmental point is modelled separately in this approach, flux predictions are based on the constraints of that particular developmental point alone and the effect of future development on metabolism in earlier stages of development is lost. In our previous work on fully expanded source leaves we highlighted a similar issue with modelling day and night metabolism separately, and demonstrated that modelling day and night phases simultaneously as a single diel FBA problem led to better predictions of leaf metabolism (Cheung et al., 2014). Applying a similar multiphase FBA approach to metabolism during tomato fruit development should therefore improve the usefulness of the computational approach.

In this study, we developed an innovative framework for modelling metabolism in expanding cells using FBA. This approach, GrOE-FBA (Growth by Osmotic Expansion - Flux Balance Analysis), accounts for the metabolic and ionic contributions to the osmotica that drive cell expansion, as well as the synthesis of protein, cell wall and cell membrane components required for cell enlargement. We show how GrOE-FBA can be used to identify the metabolic network fluxes in expanding cells, highlighting the major metabolic differences between dividing and expanding cells. We also show how GrOE-FBA can be combined with a multiphase single optimization FBA approach to study plant metabolism during organ development. This approach provided evidence that transitory starch stores are necessary for optimal fruit development, and that prevention of starch accumulation during the early stages of fruit development may result in 
smaller fruits owing to the reduced phloem uptake rate in larger tomato fruits, particularly during developmental stages where fruit expansion has been observed to be maximal.

\section{RESULTS}

\section{Modelling cell expansion using GrOE-FBA}

Cell expansion is driven by the accumulation of osmolytes and the resulting influx of water (Boyer et al., 1985). There are two key equations (See Appendix S1 for the derivation of equations 1-5 below) that allow the osmotic content of a cell to be related to its volume, and which ultimately allow FBA to be used to model metabolism in expanding cells. First, assuming that the intracellular solutions behave as ideal solutions, the total osmotic content of a cell at steady state is equal to the product of its osmolarity $\left(C_{\text {cell }}\right)$ and volume $\left(V_{\text {cell }}\right)$

$$
\sum n_{i} m_{i}=C_{c e l l} V_{c e l l}
$$

where $n_{i}$ and $m_{i}$ are the van't Hoff factor and number of moles of metabolite $i$ respectively in the cell. This equation relates changes in cell volume to changes in osmotic content, and for predicting fluxes it needs to be used in tandem with a second equation that considers the distribution of solutes between the cytoplasm and the vacuole

$$
\frac{\sum n_{j} m_{j}}{\sum n_{k} m_{k}}=\frac{V_{v}}{V_{c}}
$$

where metabolites $j$ and $k$ are vacuolar and cytoplasmic, respectively. This equation states that at steady state, the ratio of the osmotic content of the vacuole and cytoplasm is equal to the ratio of their volumes, $V_{v}$ and $V_{c}$ respectively.

Equations 1 and 2 provide the link between volume and metabolic content at cellular and subcellular levels, and they imply that including a representation of osmotic content in an FBA model should be sufficient to account for volume changes. This was achieved by introducing two pseudo-metabolites in the metabolic network to represent the osmoles associated with the accumulation of osmotically active metabolites/ions in the vacuole and cytosol $\left(O_{v a c}\right.$ and $O_{c y t}$, respectively; Figure 1a). The pseudo-metabolites took account of the expected differences in van't Hoff factor by constraining the model so that there could be no net change in the total charge of the vacuole or cytosol. To implement these constraints, two new pseudo-reactions, 'aggregator reactions', were included in the model. The first aggregator reaction, $O_{v a c}+$ $\frac{V_{v}}{V_{c}} O_{c y t} \leftrightarrow\left(1+\frac{V_{v}}{V_{c}}\right) O_{c e l l}$, defined a pseudo-metabolite, $O_{c e l l}$, to represent the overall accumulation of cellular osmolytes and constrained the model so that the ratio of accumulation of $O_{v a c}$ and $O_{c y t}$ matched $V_{v} / V_{c}$ (Equation 2). The second aggregator reaction drained $O_{c e l l}$ from the system with a flux equal to $C_{c e l l} V_{c e l l}$. This reaction satisfied the steady-state requirement and constrained the model according to equation 1 . 
As well as accumulating osmolytes, expanding cells synthesise extra cell wall, cell membrane and protein to maintain cell functions. Estimates of the additional biomass were obtained by creating a simple geometric representation of a cell assuming: (a) cells are cube-shaped; (b) the cell wall is uniformly thick and composed of cellulose only; (c) the cell membrane is uniformly thick; (d) the fraction of the total protein content of the cell in the vacuole is negligible; and (e) the cytoplasmic protein concentration is maintained during cell expansion. Based on these assumptions, if $V$ is the volume of the cube-shaped cell, $b$ is the thickness of the cell wall and $c$ is the thickness of the cell membrane (Figure 1b), then the amount of cellulose, phospholipid and protein in the cell can be estimated from the following equations (Appendix S1)

$$
\text { moles }_{\text {cellulose }}=\frac{8 b^{3}+6 b\left(V_{\text {totalcell }}\right)^{2 / 3}-12 b^{2}\left(V_{\text {totalcell }}\right)^{1 / 3}}{M W_{\text {glucose }}} \rho_{\text {cellulose }}
$$

$$
\begin{gathered}
\text { moles }_{\text {phospholipid }}= \\
\frac{8 c^{3}+6 c\left(V_{\text {totalcell }}\right)^{2 / 3}-24 b^{2} c-12\left\{\left(V_{\text {totalcell }}\right)^{1 / 3}-2 b\right\}+24 b c\left(V_{\text {totalcell }}\right)^{1 / 3}}{f_{P M} M W_{\text {phospholipid }}} \rho_{\text {phospholipid }} \\
\text { moles }_{\text {protein }}=C_{\text {protein }} V_{\text {cytoplasm }}
\end{gathered}
$$

where moles cellulose $_{\text {is }}$ the amount of cellulose in moles, $\rho_{\text {cellulose }}$ is the density of cellulose, $M W_{\text {glucose }}$ is the molecular weight of glucose, moles $_{\text {phospholipid }}$ is the amount of cell membrane phospholipids in moles, $f_{P M}$ is the fraction of the total lipid content found in the plasma membrane, $\rho_{\text {phospholipid }}$ is the density of cell membrane phospholipids, $M W_{\text {phospholipid }}$ is the molecular weight of membrane phospholipid, moles protein is the amount of protein in moles (based on how a unit protein is represented in metabolic models), $C_{\text {protein }}$ is the molar concentration of protein in the cytoplasm (based on the molar mass of a unit protein as represented in the metabolic model) and $V_{\text {cytoplasm }}$ is the volume of the cytoplasm.

The demand for osmolytes and biomass elements required to support a change in cell volume can be estimated from the difference in the amount of these metabolites for the initial and final cell volumes. For example, the cellulose demand for when a cell changes its volume from $V 1$ to $V 2$ can be calculated as follows,

$$
\text { flux }_{\text {cellulose }, V 1 \rightarrow V 2}=\frac{\text { moles }_{\text {cellulose }, V 2}-\text { moles }_{\text {cellulose }, V 1}}{\text { time }_{, V 1 \rightarrow V 2}}
$$

where moles $_{\text {cellulose } V 1}$ and moles $_{\text {cellulose,V2 }}$ are moles of cellulose when the cell has a volume of $V 1$ and $V 2$, respectively; and time,$V 1 \rightarrow V 2$ is the time the cell takes to change its volume from $V 1$ to $V 2$.

In this manner, by combining previously described osmotic constraints (based on equations 1 and 2) with biomass constraints (based on equations 3, 4 and 5), it is possible to perform FBA while accounting for cell volume. 


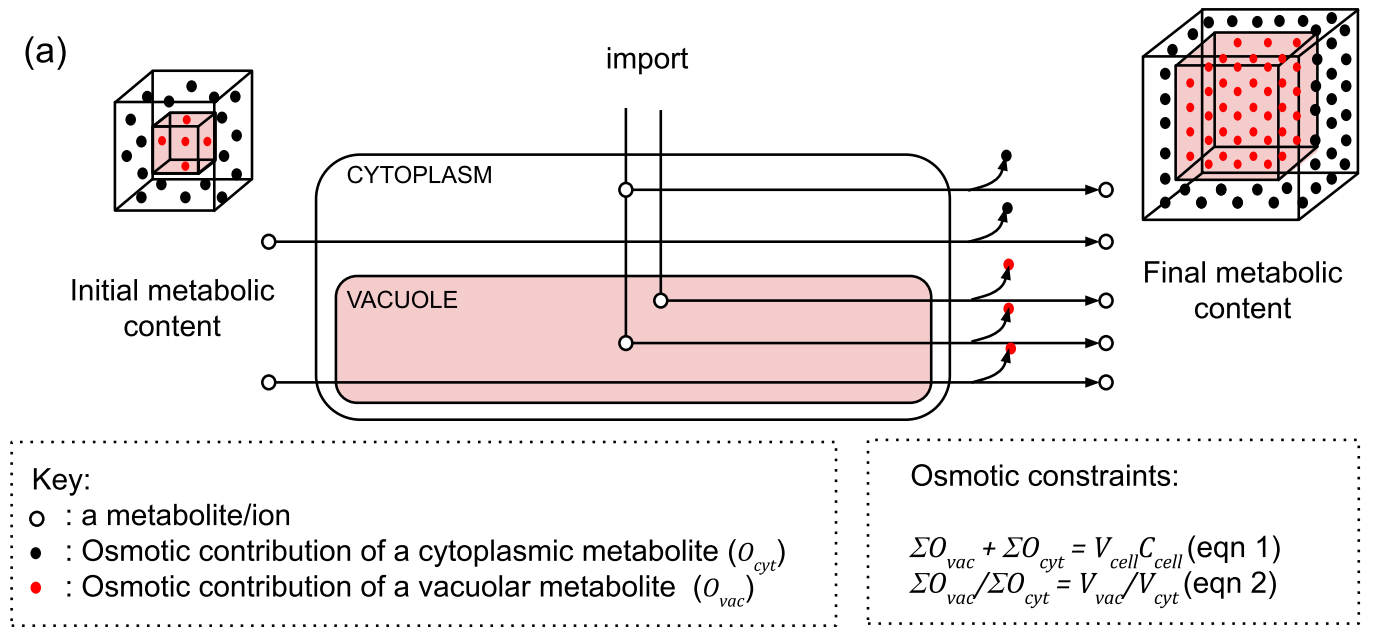

(b)

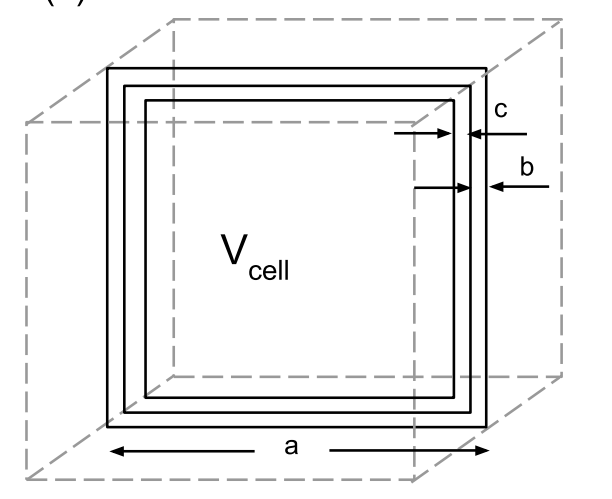

$$
\begin{aligned}
& V_{\text {cell }}=a^{3} \\
& \begin{array}{r}
\text { cellwall } \\
=
\end{array}=V_{\text {totalcell }}-V_{\text {cellwithcellmembrane }} \\
& \quad=8 b^{3}+6 a^{2} b-12 a b^{2} \\
& \quad \begin{array}{l}
\text { cellmembrane } \\
=
\end{array} \quad V_{\text {totalcell }}-\left(V_{\text {cell }}+V_{\text {cellwall }}\right) \\
& =8 c^{3}+6 a^{2} c+24 b^{2} c-12 c^{2}(a-2 b)-24 a b c
\end{aligned}
$$

Figure 1: Modelling cell expansion in cube-shaped pericarp cells. (a) Cell expansion is driven by the accumulation of soluble metabolites and ions in the vacuole and cytosol. Accumulation of osmotically active species in the GrOE-FBA model is accompanied by the accumulation of pseudometabolites $O_{v a c}$ or $O_{c y t}$, representing the contribution of the accumulating metabolite/ion to the osmoticum of the vacuole or cytosol respectively. According to equation 1, the sum of the vacuolar and cytosolic osmoles is equal to the product of the volume $\left(V_{\text {cell }}\right)$ and osmolarity $\left(C_{\text {cell }}\right)$ of the cell. According to equation 2, the ratio of vacuolar and cytosolic osmoles is equal to the ratio of the vacuolar $\left(V_{v a c}\right)$ and cytosolic $\left(V_{c y t}\right)$ cell fractions. (b) The volumes of the cell wall and cell membrane were calculated by subtracting the remaining parts of the cell from the total cell volume. $a$, edge length of the cell; $b$, cell wall thickness; $c$, cell membrane thickness. Changes in edge length lead to changes in cell volume, but the cell wall and cell membrane thickness are assumed to be constant. 


\section{Validation of the equations used to estimate the change in biomass during cell expansion}

The cell wall, lipid and protein contents of tomato pericarp cells during fruit development were determined (Data S1) and the results compared with predictions based on equations 3-5 (Figure 2). Pericarp cell membrane phospholipid composition was assumed to be composed of phosphatidyl ethanolamine (PE), phosphatidyl choline (PC) and phosphatidic acid (PA) based on published data in cherry tomato (Guclu et al., 1989) and the relative amounts of PE, PC and PA

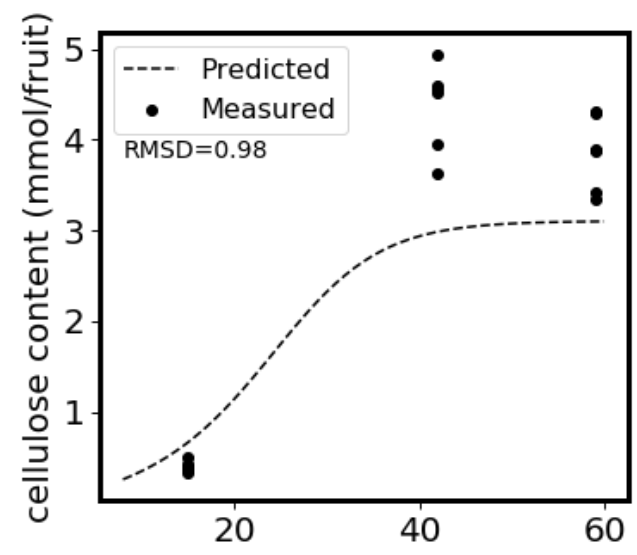

Figure 2: Cellulose, lipid and protein contents of tomato pericarp cells. The predicted curves are based on equations 3-5 for cellulose, membrane phospholipid and protein content respectively.
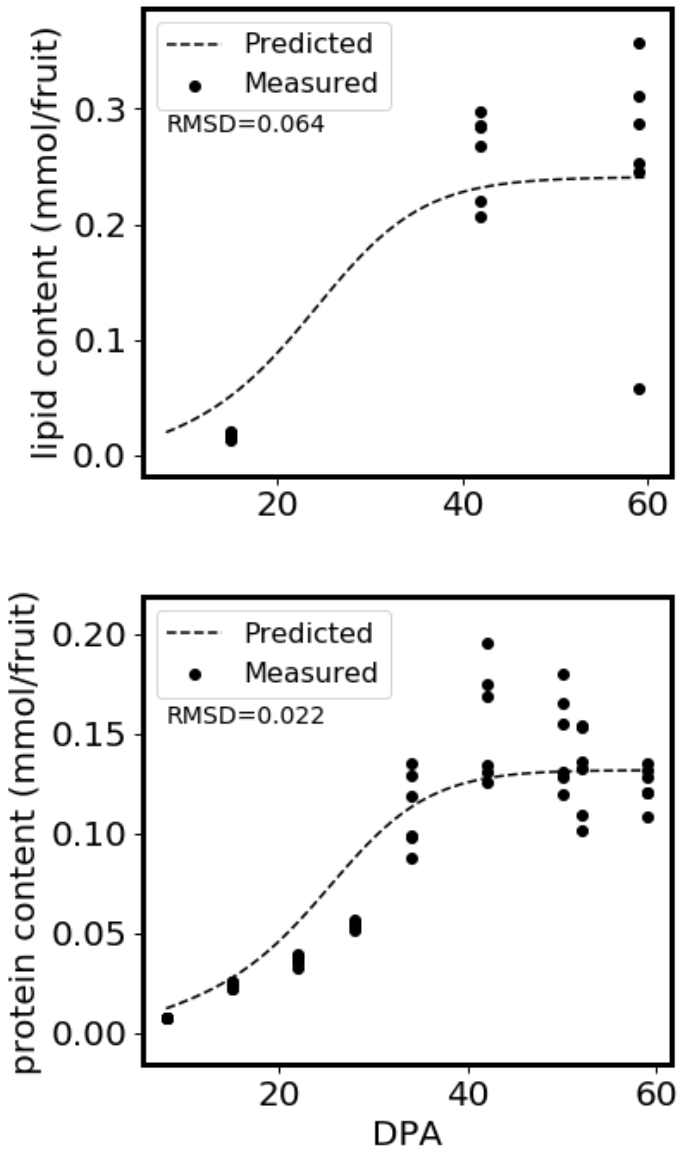
were used to estimate values for $\rho_{\text {phospholipid }}$ and $M W_{\text {phospholipid. The value of } f_{P M} \text { was }}$ estimated from data published in tobacco leaves (Cacas et al., 2016) and assumed to be constant throughout fruit development. Values of other parameters required in the equations were collected from published data or measured experimentally (Table S1).

Figure 2 shows that equations 3-5 generated a good match to experimentally measured values for tomato fruit. The slight underestimation of fruit cellulose content is likely due to the assumption of the cells being geometric cubes with a constant cell wall thickness, which does not account for increased cell wall thickness around corners of the cell (Legland et al., 2012). Thus, a simple geometric model can be used to predict increases in cellulose, phospholipid and protein content during cell expansion, and this allows these major biomass outflows from the metabolic network to be estimated, avoiding the need for direct measurements.

\section{Application of GrOE-FBA to expanding tomato cells}

Because of the energy cost of synthesising cellular macromolecules such as protein, lipid and carbohydrates (Schwender and Hay, 2012), it is generally assumed that synthesis of new cells is more expensive than expanding existing cells (Lynch, 2019; Taiz, 1992). However, even during cell expansion, new macromolecules need to be produced and the synthesis and accumulation of osmolytes to drive cell expansion also represents a significant cost. The GrOE-FBA framework allows the costs of cell expansion to be accurately computed and can be compared to a computation of the costs of cell division computed using conventional FBA with a biomass objective. To do this, we modelled rapidly dividing tomato pericarp cells in culture using data from (Rontein et al., 2002) and compared the resulting model to one of rapidly expanding pericarp cells in fruit. Both models were constructed using a minor updated version (PlantCoreMetabolism_v1_2) of our previously published core stoichiometric model of primary plant metabolism (Shameer et al., 2018). To make the models comparable, they were provided with the same precursors: glucose as the sole carbon source, as well as $\mathrm{NH}_{4}{ }^{+}, \mathrm{O}_{2}, \mathrm{PO}_{4}^{-}$and $\mathrm{SO}_{4}{ }^{-}$. The same objective function of minimization of the sum of fluxes was applied to both models. Experimental data was used to constrain the rate of biomass production in the dividing cell model to $2 \mathrm{mg} \mathrm{DW} / \mathrm{mL} /$ day, the fastest rate reported in the Rontein et al. (2002) study. The rate of cell expansion in the expanding cell model was set to that of fruit at 26 days post anthesis (DPA) where the fastest rate of fruit growth was observed (Beauvoit et al., 2014). The initial exploration of the expanding cell model included an additional component to the objective function: to maximise the organic solute content while satisfying the osmotic constraint (see subsequent explanations and discussions).

Figure 3 summarizes the results of this comparison for equivalent numbers of cells and the complete list of predicted fluxes is provided in Data S2. Comparison of the metabolic fluxes in the two models revealed that dividing cells have higher fluxes of cellulose, protein, starch and lipid biosynthesis as expected; while the expanding cells accumulated significantly more organic solutes, both in the vacuole and cytosol (Figure $3 a$ and $3 b$ ). This accumulation of organic solutes 
in the expanding cell model increased the carbon demand of the model, and somewhat surprisingly, the overall rate of glucose consumption was substantially higher in the expanding cell model $(5.82 \mathrm{mg} / \mathrm{mL}$ in a day) than in the dividing cell model $(3.57 \mathrm{mg} / \mathrm{mL} /$ day). The flux maps (Figure $3 \mathrm{a}, \mathrm{b}$ ) reveal that a substantial proportion of this additional glucose (66\% of carbon taken up by the cell) was transported into the vacuole to satisfy the osmotic requirement for cell expansion. But it is also apparent that there were comparably high fluxes of glycolysis, and even higher TCA cycle flux, relative to the dividing cell model, suggesting that the energy demand of cell expansion is comparable to that of cell division. To provide a more precise quantitative comparison of energy costs, we constructed an energy budget in the two systems by collating all the fluxes in the models that required ATP consumption or led to ATP production (Figure 3d). The total ATP demand of the expanding cells was $0.16 \mathrm{mmol}$ ATP/mL/day $(0.10 \mathrm{mmol} \mathrm{ATP} / \mathrm{mL} /$ day when excluding non-growth associated maintenance or NGAM) and that of the dividing cells was $0.14 \mathrm{mmol} / \mathrm{ATP} /$ day $(0.08 \mathrm{mmol}$ ATP $/ \mathrm{mL} /$ day when excluding NGAM). This showed that indeed both models have very similar energy demands. Looking at the breakdown of energy expenditure (Figure $3 \mathrm{~d}$ ) it is apparent that although the expanding cell model devoted considerably less ATP to synthesis of protein, lipid and cell wall (12\% compared to $44 \%$ in dividing cells), this was offset by a large increase in the cost of solute biosynthesis and accumulation which represented $50 \%$ of the ATP budget in the expanding cell model compared to only $11 \%$ in dividing cells (Figure $3 \mathrm{~d}$ ).

Given that maximization of organic solute was a component of the objective function of the expanding cell model, the very high rate of accumulation of glucose to satisfy the osmotic constraint may be a feature of how we set up the model. Although it is known that fruit cells do contain high amounts of hexose sugars (Biais et al., 2014), it is likely that inorganic solutes contribute to the osmotic balance and this would affect the total energy cost of osmolyte production and accumulation. To explore this, we removed the maximization of organic solute objective and just used minimization of the sum of fluxes as the sole objective, as in the dividing cell model. This led to a significantly lower glucose consumption rate in expanding cells (1.61 $\mathrm{mg} / \mathrm{mL} /$ day) but the overall ATP demand remained comparable to the previous model $(0.12$ $\mathrm{mmol}$ ATP/mL/day). The predicted flux distribution (Figure $3 \mathrm{c}$ ) revealed that the model was exclusively using inorganic ions to satisfy the osmotic constraints. In reality expanding cells are expected to accumulate both organic and inorganic solutes to facilitate cell expansion, so the predicted energy demand of the expanding and dividing cells are comparable. These results demonstrate that cell expansion is not necessarily a cheap option for plant growth as previously argued (Taiz, 1992).

Many similarities between the three systems (dividing cells, expanding cells accumulating organic solute and expanding cells accumulating solely inorganic solute) were apparent. For example, in each system, more than $75 \%$ of the ATP demand was met by mitochondrial ATP synthesis $(75 \%$, $76 \%$ and $79 \%$ respectively) and NGAM was found to be a significant energetic drain (45\%, 39\% and $51 \%$ of the total ATP demands respectively). The second and third largest energetic demands were the ATP cost of maintaining the plasma membrane proton gradient (PM-ATPase) during nutrient uptake $(18 \%, 21 \%$ and $30 \%$ of the total ATP demands respectively) and the hexokinase 
flux (14\%, 14\% and 7\%). While the basis for NGAM was identical in the three models, the PMATPase and hexokinase flux are dependent on the carbon demands of the model. As a result, the energy demand of the system is significantly influenced by the carbon demand for biosynthesis.

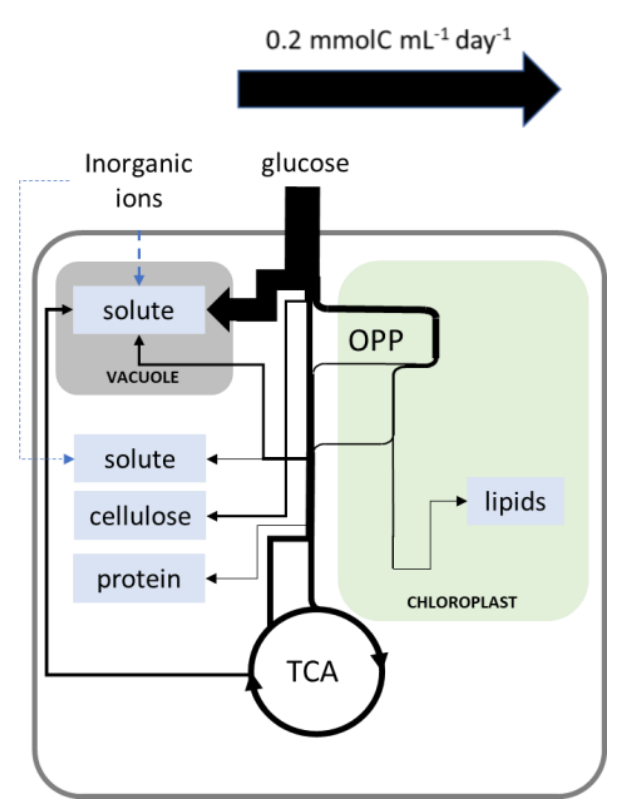

(a)

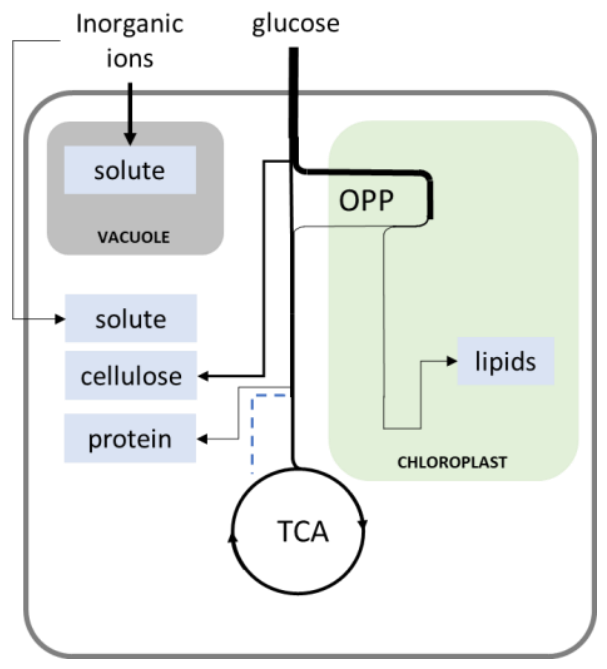

(c)

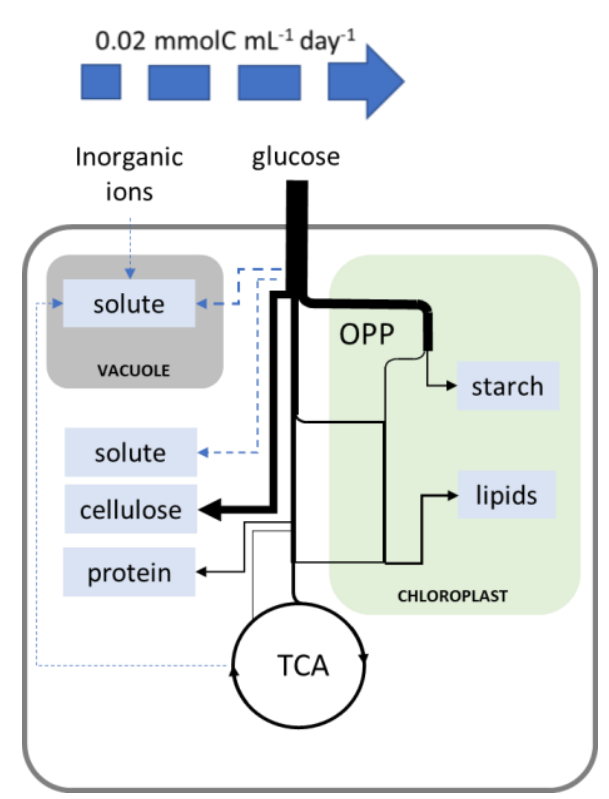

(b)

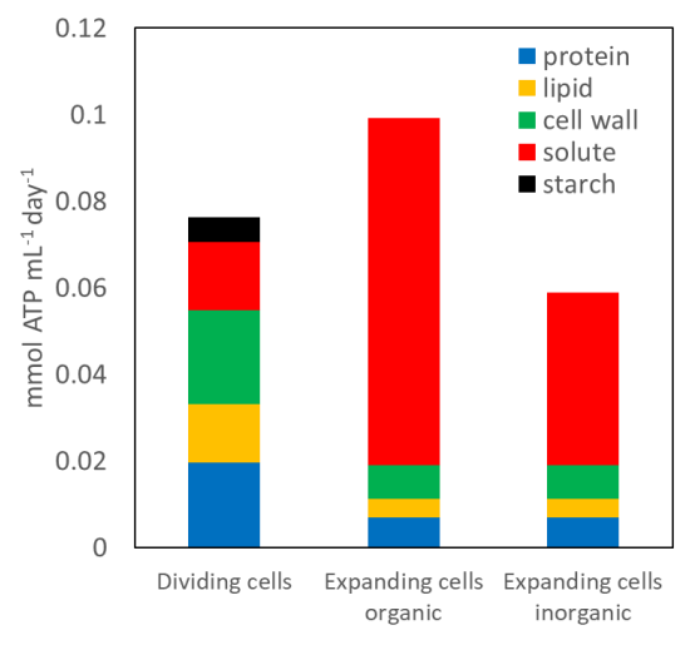

(d)

Figure 3: Flux prediction in expanding and dividing tomato cells using GrOE-FBA. Predicted metabolic fluxes in: (a) expanding cells accumulating only organic solutes; (b) dividing cells; and (c) expanding cells accumulating only inorganic solutes. Organic and inorganic fluxes are represented as $\mathrm{mmolC} / \mathrm{mL} /$ day and $\mathrm{mmol} / \mathrm{mL} /$ day respectively with the thickness of the lines scaled to match the fluxes. Values of all the predicted fluxes are given in Data S2. (d) ATP budgets for solute accumulation and for the biosynthesis of protein, lipid, cell wall, and starch, deduced from the three predicted flux maps. 


\section{A multi-phase metabolic model of primary metabolism in developing tomato fruit}

To investigate the changing metabolic requirements for growth by cell expansion during organ development, pericarp metabolism was modelled using GrOE-FBA in the expansion and ripening stages of developing tomato fruit by dividing the time-course from 8 days post anthesis (DPA) to red ripe stage (59 DPA) into ten developmental substages. Ten copies of PlantCoreMetabolism_v1_2, each representing one of these substages, were combined to generate a 10-phase constraint-based model of primary metabolism in tomato pericarp cells. To allow for the accumulation and utilisation of sugars (glucose, fructose and sucrose), amino acids (including GABA) and organic acids (malate and citrate) in each phase, reactions transferring metabolites and ions from one phase to the next, called "linker reactions", were added to the cytosol and vacuole of the model. Similarly, transfer of starch from one phase to the next (allowing for accumulation and utilisation of starch) was enabled via linker reactions in the plastid. The linker reactions and the multiphase nature of the model ensure that metabolism in each stage of fruit development depends not only on metabolism in the previous developmental stages but is also influenced by that of future developmental stages. Each phase in the multiphase also had access to the xylem and phloem, and was subjected to biomass requirements. A full schematic representation of the model is presented in Figure 4.

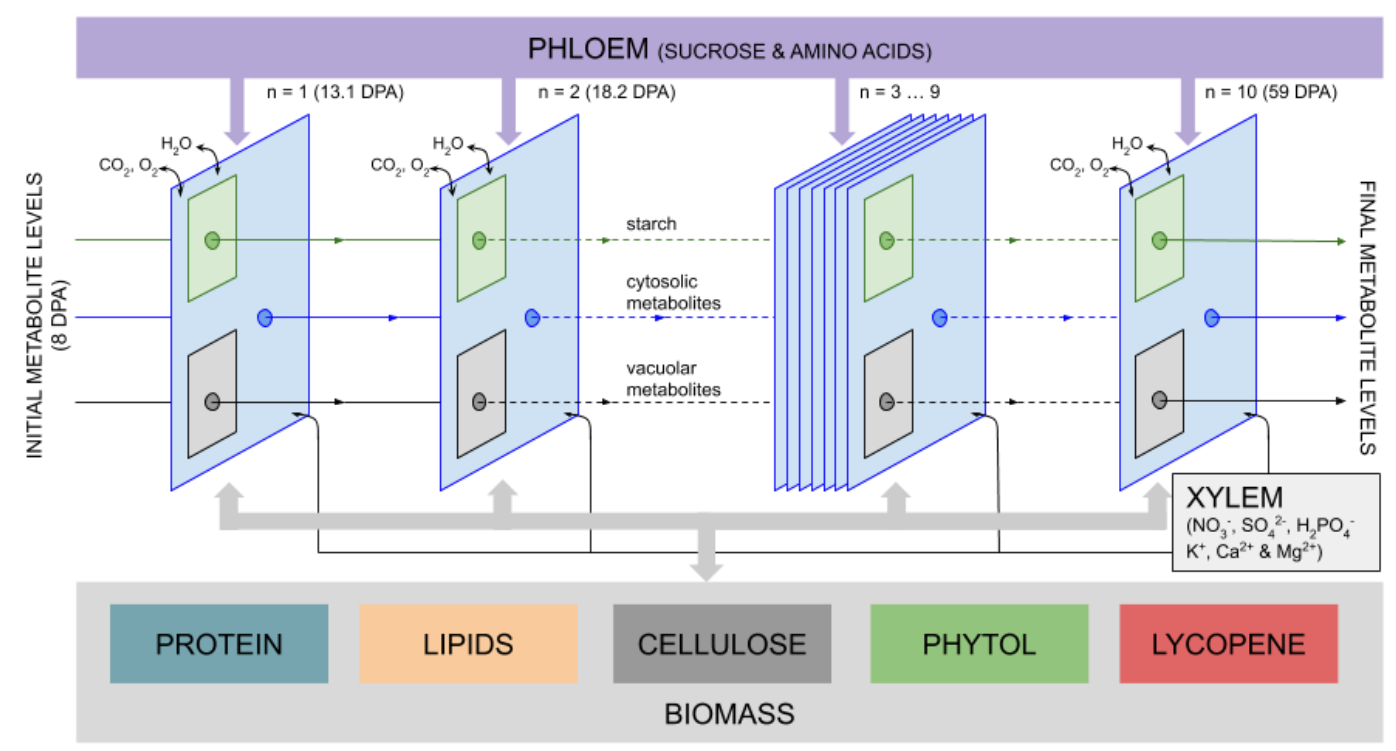

Figure 4: Schematic representation of the multiphase model of tomato fruit development. Fruit development from 8 days post anthesis (DPA) to 59 DPA was divided into 10 phases. Each phase has access to the indicated nutrients from the mother plant via xylem and phloem and is subject to biomass demands. Accumulation of certain metabolites and ions were permitted in each phase, facilitated in the model by 'linker reactions' that allow the accumulated metabolites / ions to be passed to the next phase. 
The initial metabolite content of the fruit pericarp at 8DPA was established by adding source reactions (reactions that represent the import of metabolites from outside the modelled system) for sucrose, fructose, glucose, amino acids, GABA, organic acids and starch to the first phase of the model. The flux through these source reactions was constrained using the experimentally determined soluble metabolite content of 8 DPA fruits (Data S1). The soluble metabolite content of red ripe tomato fruits (59 DPA) (Data S1) was used to constrain the relative proportions of the soluble metabolites in the final model phase of the model by introducing appropriately constrained sink reactions. Previously published data on vacuolar $\mathrm{pH}$ during fruit development in cherry tomatoes (Rolin et al., 2000) was used to set the vacuolar pH for the ten phases and thus the abundance of the different metabolite charge states for each phase. A data-based constraint was also applied for the maximal rate of uptake of nutrients into the fruit from the phloem (see Materials and Methods). The multiphase developing fruit model was solved as a single parsimonious FBA (pFBA) problem, an approach similar to previously published multiphase (Cheung et al., 2014; de Oliveira Dal'Molin et al., 2015; Shameer et al., 2018) and multi-tissue (Grafahrend-Belau et al., 2013; de Oliveira Dal'Molin et al., 2015; Scheunemann et al., 2018; Shaw and Cheung, 2018) constraint-based models, with the maximization of fruit soluble metabolite content as the objective. Fruit content and composition is key in increasing yield in tomato cultivation, hence, the maximization of flux through the reaction representing the accumulation of soluble metabolites in ripe tomatoes was deemed an apt objective function for the model. NGAM, nutrient uptake from the phloem and the osmotic constraints based on equations 1 and 2 were implemented as described in Materials and Methods.

\section{A multiphase developing tomato fruit model predicts realistic final fruit metabolite content}

Figure 5 depicts the influence of the various constraints on the predictions of the multiphase developing fruit model. Optimal flux distributions of the model without the osmotic and biomass constraints to describe cell expansion and with no upper limit on phloem uptake rates predicted unrealistically high fruit organic solute content ( $5000 \mathrm{mOmol} /$ fruit; Fig. 5a). The introduction of osmotic constraints on the system greatly reduced the final fruit organic solute content to 24.5 mOsmol/fruit (Fig. 5b). This value was just 7.5\% lower than the measured value (26.5 $\mathrm{mOsmol} /$ fruit). The imposition of biomass demand fluxes did not affect the predicted ripe fruit organic content, although it did cause small variations in predicted fruit content during the early stages of fruit expansion (Fig. 5c). Limiting the phloem uptake rate had no effect on the predicted organic content of ripe fruits, but it did reveal a requirement for a transitory carbohydrate store in expanding fruits (Fig. 5d).

In order to understand the factors driving metabolism during fruit development, predicted fruit metabolic content during development was analysed (Table 1). From Table 1, it can be seen that the soluble organic content contributes a significant fraction of fruit content particularly during the later stages of fruit development. On the other hand, cellulose, lipid and protein content form a fixed fraction of predicted fruit content throughout development. The optimal flux distribution 
and a fully constrained version of the multiphase model are available in Data S2 and Data S3, respectively.
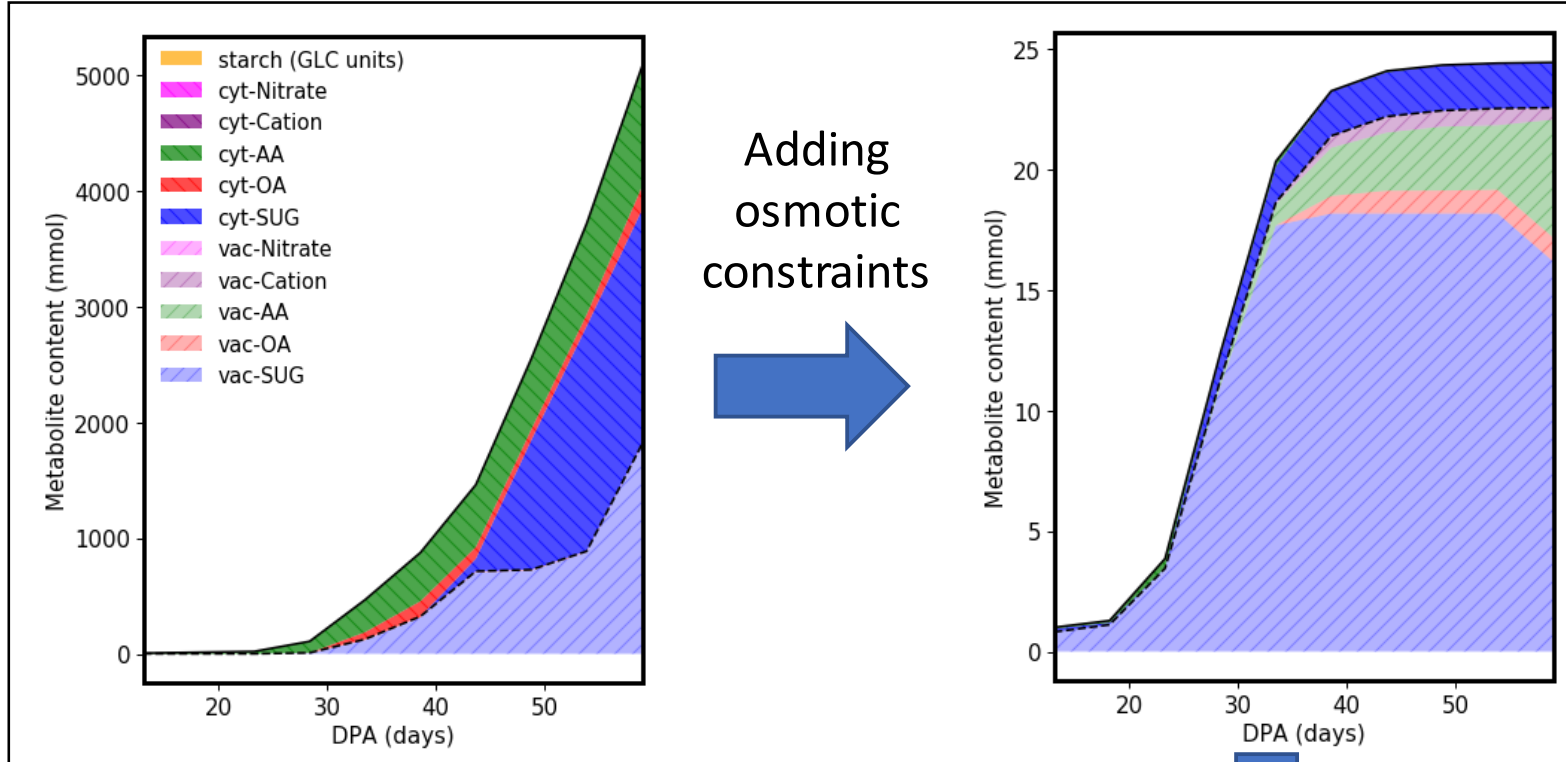

\section{Adding biomass constraints}
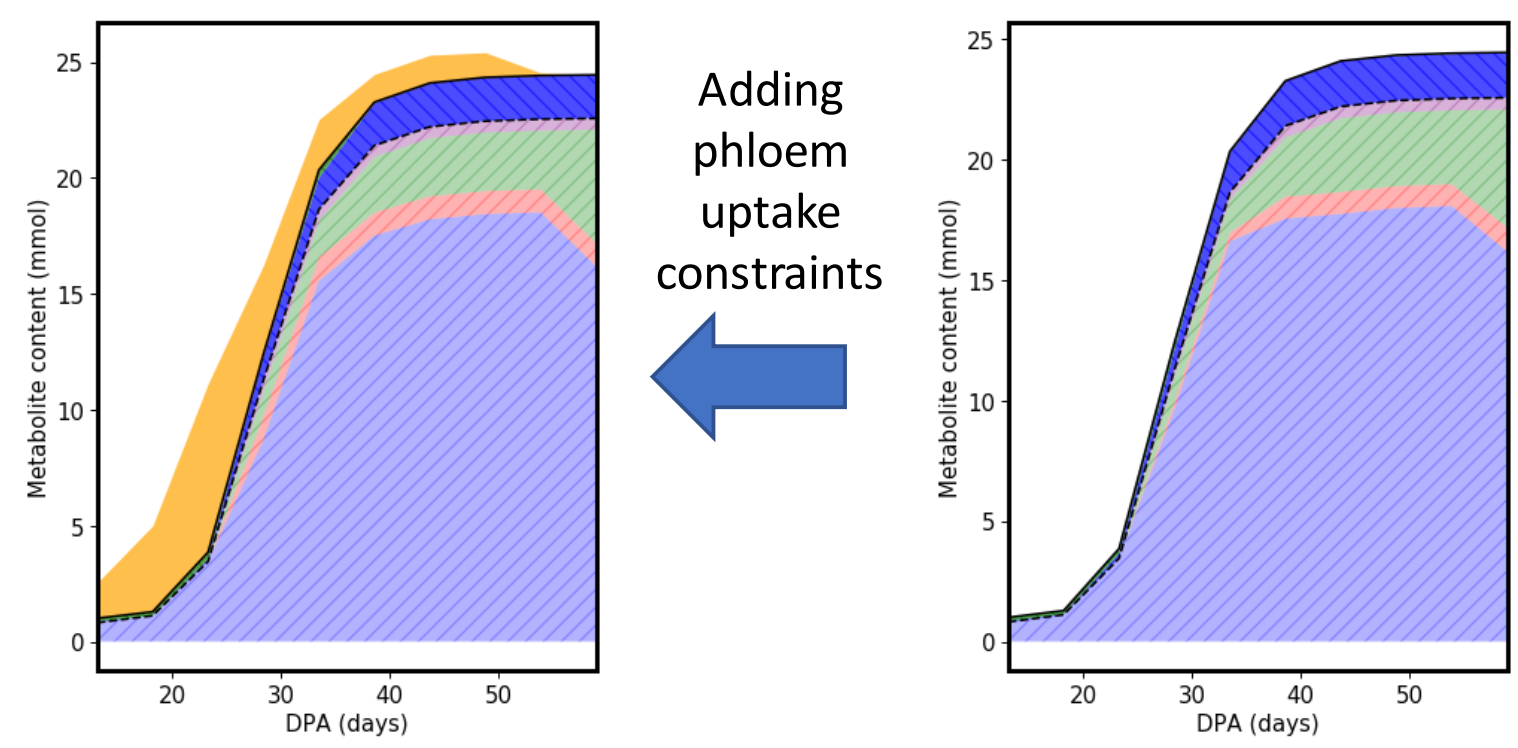

Figure 5: Impact of model constraints on the predicted metabolite contents of developing tomato fruit. The charts show the sequential effect on the predicted metabolite contents of adding osmotic, biomass and phloem uptake constraints to the model. In the absence of these constraints the predicted total metabolite content greatly exceeded the expected value, whereas after applying the constraints there was close agreement between the measured and predicted values. AA, amino acids; OA, organic acids; SUG, sugars (glucose, fructose and sucrose). 


\begin{tabular}{|ccccccc|}
\hline Phase & \multicolumn{3}{c}{ fruit content (\% fruit DW) } & fruit DW \\
(DPA) & Cellulose & Phospholipids & Protein & Starch & Organic solutes & (mg) \\
\hline $8-13.1$ & $9.49 \%$ & $2.81 \%$ & $1.1 \%$ & $27.6 \%$ & $59.0 \%$ & 927.6 \\
$13.1-18.2$ & $8.04 \%$ & $2.39 \%$ & $0.91 \%$ & $34.8 \%$ & $53.9 \%$ & 1989 \\
$18.2-23.3$ & $6.35 \%$ & $1.88 \%$ & $0.72 \%$ & $31.0 \%$ & $60.1 \%$ & 4104 \\
$23.3-28.4$ & $7.45 \%$ & $2.21 \%$ & $0.87 \%$ & $13.4 \%$ & $76.1 \%$ & 4811 \\
$28.4-33.5$ & $8.21 \%$ & $2.44 \%$ & $0.97 \%$ & $6.20 \%$ & $82.2 \%$ & 5207 \\
$33.5-38.6$ & $8.33 \%$ & $2.47 \%$ & $0.99 \%$ & $2.92 \%$ & $85.3 \%$ & 5587 \\
$38.6-43.7$ & $8.15 \%$ & $2.42 \%$ & $0.97 \%$ & $2.74 \%$ & $85.7 \%$ & 5930 \\
$43.7-48.9$ & $8.33 \%$ & $2.47 \%$ & $0.99 \%$ & $2.35 \%$ & $85.9 \%$ & 5869 \\
$48.9-54.0$ & $8.78 \%$ & $2.61 \%$ & $1.04 \%$ & $0.27 \%$ & $87.3 \%$ & 5562 \\
\hline
\end{tabular}

Table 1: Predicted increase/decrease in fruit content by the multiphase developing fruit model.

\section{Comparing model predictions to experimental measurements}

Figure 6 compares the fruit content of selected metabolites predicted by GrOE-FBA with the experimentally determined values. The complete dataset for 22 solutes is provided in Supplementary Figure S1. The model was capable of making accurate predictions for glucose, fructose, glutamine and glutamate, despite being free to choose which metabolites it accumulated to satisfy the osmotic constraint. These four metabolites formed $88.6 \%$ of organic osmolytes in the pericarp cells and their accurate prediction by the osmotically-constrained model suggests that their pattern of accumulation in developing tomato fruit represents an efficient way to drive osmotic expansion. Some other metabolite levels, including those of malate and citrate, were predicted with reasonable accuracy during the later stages of fruit development; while for others, including sucrose and GABA, it was not possible to predict the observed pattern of accumulation. This suggests that the accumulation of these metabolites is not primarily osmotically driven and that other aspects of fruit physiology may drive their accumulation during fruit development. For example, factors such as insect resistance, texture and flavour, all have an impact on determining fruit composition during development (Tohge et al., 2014; Cohen et al., 2014; Takayama and Ezura, 2015). Translating these factors into constraints for a metabolic model would be challenging, since the measured content of some of the poorly-predicted amino acids (aspartate and serine) fell within the FVA ranges of the model (Figure S1) but applying extra constraints to the system may improve model prediction.

\section{A transitory carbohydrate store is required when phloem nutrient uptake is limited}

If nutrient influx from the phloem was unlimited, then the nutrient requirement for fruit development was predicted to peak in phases 4 and phase 5 (23.3-33.5 DPA; Fig. 7a). In contrast when an upper bound on phloem uptake (Fig. 7b) was imposed, based on experimental data, the model predicted the need for transitory carbohydrate storage (Fig. 7c), a well-documented behaviour of tomato fruits (Ho and Hewitt, 1986; Gillaspy et al., 1993). When phloem uptake rate limits were removed from the model there was no accumulation of starch (Figure 7d), suggesting 


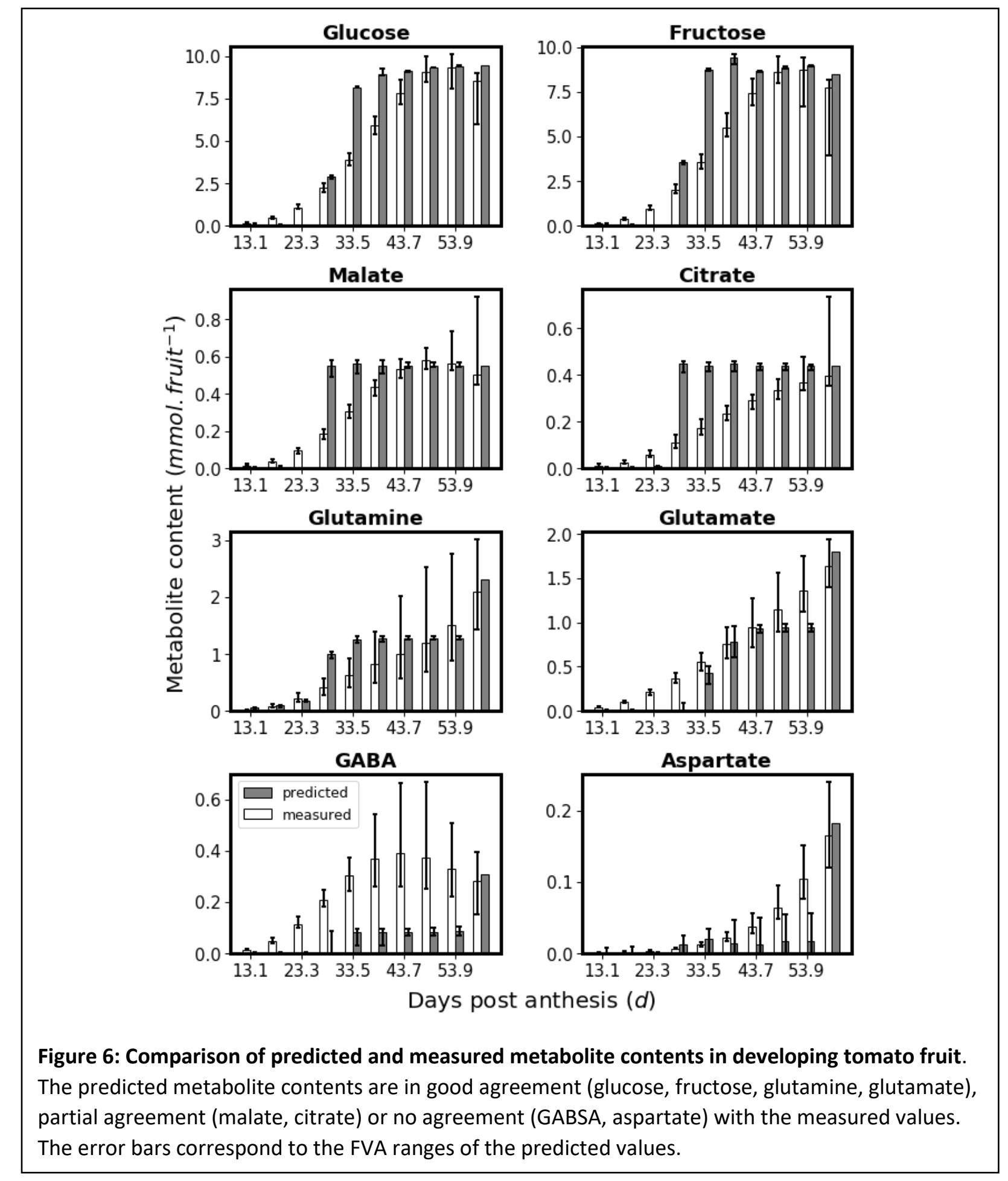

that the accumulation of starch was associated with the phloem influx limits and metabolic demand. Moreover, preventing the accumulation of starch caused a $40 \%$ drop in the organic content of the fruit, demonstrating the significance of transitory starch storage in developing tomato fruits. 


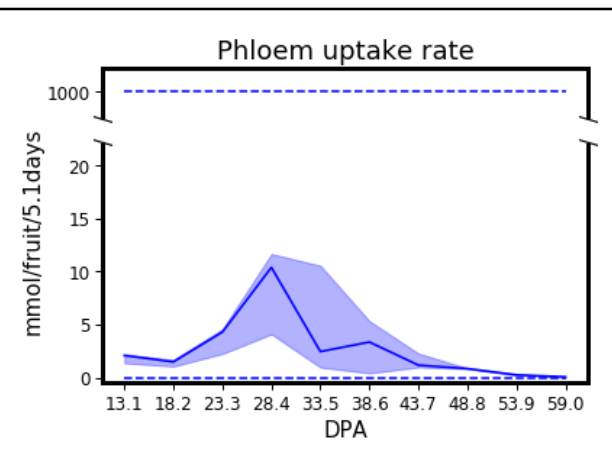

(a)

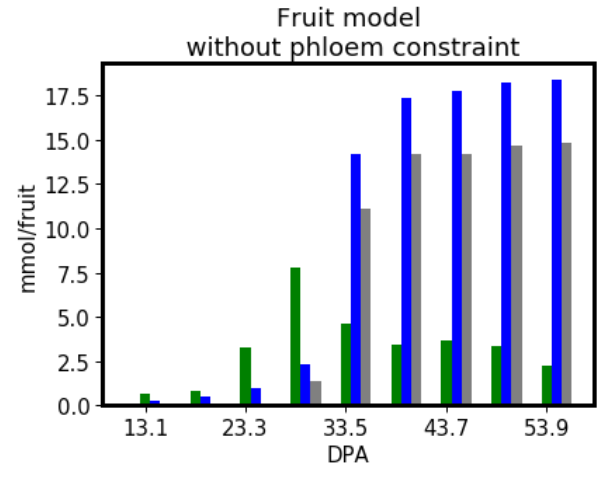

(c)

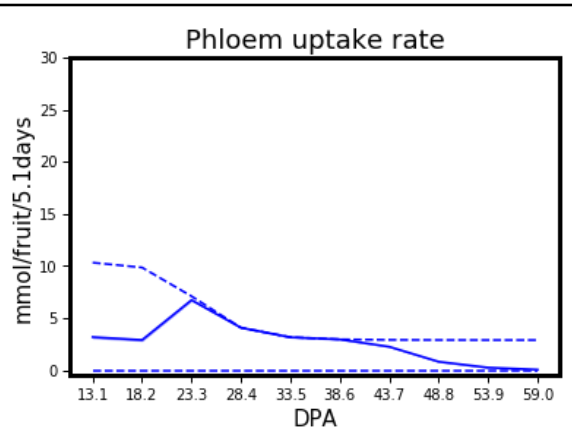

(b)

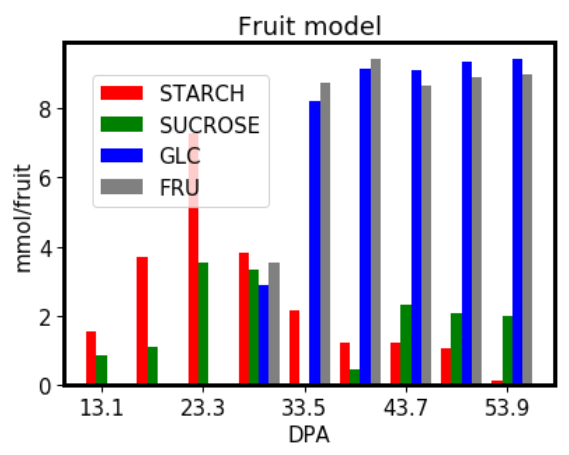

(d)

Figure 7: Impact of phloem uptake rate on the need for a transitory carbohydrate store during tomato fruit development. The multiphase GrOE-FBA model was run with the phloem uptake rate either (a) effectively unconstrained (allowing the model to choose a rate between 0 and 1000 $\mathrm{mmol} /$ fruit/5.1 days) or (b) constrained with the upper bound based on the measurements of Walker and Ho $(1977 a, b)$. The upper and lower bounds of the phloem uptake rate are shown as dotted lines, and the optimal value chosen by the model as a solid line, together with the FVA range (shaded) for the solution. Applying the upper bound to the phloem uptake rate creates a carbon and/or energy limitation in phases 4 and 5 (28.4-33.5 DPA) of the multiphase fruit model. The predicted starch and soluble sugar contents obtained with the phloem uptake rate either (c) unconstrained, or (d) constrained, show that phloem uptake rate constraints are responsible for the temporary carbohydrate buildup observed in the early stages of fruit development.

\section{DISCUSSION}

\section{GrOE-FBA: proof of concept in the comparison of expanding and dividing cells}

GrOE-FBA was developed to predict metabolic network fluxes in cells undergoing osmoticallydriven cell expansion. As a proof of concept, GrOE-FBA was used to highlight the differences between metabolism in dividing and expanding cells, and the analysis led to the conclusion that cell expansion does not necessarily put a smaller requirement on cellular resources than cell division. While it is not surprising that differences existed between metabolism in dividing and expanding cells, quantitative network-level comparisons have not been made before. The two systems chosen here for comparison were dividing cells in heterotrophic cell suspension cultures 
and expanding cells in developing tomato fruits. A more appropriate comparison would be to model metabolism during the very early phase of tomato fruit development, when cell division dominates, and the later phases when expansion dominates. However, there is very little biochemical data to constrain such a cell division model, due to the very small size of young plant organs in the cell division phase. Even so, the marked difference in the predicted metabolic fluxes of dividing and expanding cells (Fig. 3) implies that FBA studies on plant tissues such as growing leaves (Yuan et al., 2016; Shaw and Cheung, 2018) and roots (Grafahrend-Belau et al., 2013; Shaw and Cheung, 2018), which generally use a biomass objective even though measurable growth in such organs is largely by expansion, could be predicting erroneous flux distributions.

\section{GrOE-FBA: application to tomato fruit development}

GrOE-FBA was combined with multiphase modelling to analyse metabolism in developing tomato fruit. The approach required minimal constraints: a knowledge of the cell volume changes during expansion, an estimate of the volume ratio of vacuole to cytosol, and an estimate of protein concentration ( $C_{\text {protein }}$, Eq. 5 ). Using these constraints, it was possible to make surprisingly accurate predictions about the accumulation of biomass components and the principal osmotic metabolites that drive cell expansion in tomato fruit (Figs 5 and 6). The same approach could be applied to the growth of other organs such as leaves and roots.

Previous modelling studies taking into account cell expansion and metabolism were based on analysis of enzyme kinetics and were capable of exploring only limited aspects of metabolism because of the difficulty of gathering or estimating large numbers of kinetic parameters (Beauvoit et al., 2014). Previous work using FBA modelling to analyse metabolism in developing tomato fruits used separate models for each stage of development (Colombié et al., 2015). Such highly constrained models can provide answers to the question "What is happening?" but cannot answer the question "Why is it happening?". For example, with this approach it has been shown that breakdown of transitory starch is the underlying cause of the respiratory climacteric in tomato fruit (Colombié et al., 2017) but it was not possible to explain the purpose of the transitory starch accumulation. This is because starch accumulation and degradation were constraints of the model and not predictions. In contrast, starch accumulation and degradation in the multiphase GrOE-FBA model are system-level predictions that depend on the metabolic demand on the system and the availability of nutrients from the phloem, throughout development.

\section{GrOE-FBA: insights into tomato fruit development}

Two major biological insights emerged from the analysis of the GrOE-FBA model of tomato fruit development. First, we demonstrate that transitory carbohydrate stores are only predicted by the model if a constraint is added that gradually decreases the rate of influx of nutrients from the phloem. Our model demonstrates that due to the decline in phloem influx during development, accumulation of starch (or other carbohydrates such as sucrose) in the earlier stages of fruit development is required to meet the carbon demand in later stages. The question then arises as 
to why the phloem influx into a fruit declines below that which is required to maintain its metabolic requirements. One possibility is that due to the staggered initiation of fruits along a truss, it is necessary to progressively reduce the share of phloem nutrients taken by maturing fruit to allow younger fruits, that have lower sink strength, to develop successfully. Temporal extension of starch synthesis has been reported to result in increased fruit size (Petreikov et al., 2006; Petreikov et al., 2009). This is in agreement with our hypothesis. Increased sucrose demand owing to starch synthesis will increase the sink strength of smaller fruits. Once the fruits are bigger, the greater transitory starch stores will reduce their sink strength, resulting in more phloem constituents being available to the smaller fruits.

The second biological insight is the relatively minor impact biomass demand had on developing fruit metabolism (Fig. 4). It is known that cell expansion results in an increase in cell wall and cell membrane content. Protein content of cells is also thought to increase in order to maintain the optimal concentration required for unhampered metabolism. In most FBA models of growing plant tissues to date, synthesis of these biomass components is the main drain on the metabolic system. The GrOE-FBA model demonstrates that for tissues growing by expansion of existing cells, demand for these biomass elements imposes only a small fraction of the metabolic cost. Instead, the dominant demand on metabolism was solute accumulation for osmotically-driven cell expansion. Accumulation of solutes was responsible for most of the gain in fruit DW during 18-43.7 DPA (Table 1). From this we can conclude that the drivers for metabolism in expanding cells are significantly different from dividing cells and that osmolarity-based constraints such as GrOE-FBA applied in this study, are necessary to model metabolism in tissues growing by cell expansion.

\section{GrOE-FBA: limitations of the approach}

GrOE-FBA is a modified form of FBA and hence inherits its limitations (Sweetlove and Ratcliffe, 2011), including not being able to predict futile cycles. A substantial fraction of the energy consumption in a tomato cell suspension has been attributed to the operation of such cycles (Rontein et al., 2002) and the FBA model is unable to capture this energy expenditure. While this might explain the discrepancy between the glucose consumption rate of the model (3.57 $\mathrm{mg} / \mathrm{mL} /$ day) and the value reported in the literature (glucose influx rate for day 4 is 5.34 $\mathrm{mg} / \mathrm{mL} / \mathrm{day}$ ), it should also be noted that the method used to estimate the futile cycles has been shown to be confounded by the subcellular structure of the metabolic network (Kruger et al., 2007).

Another limitation of GrOE-FBA, is that it focuses on the osmotic significance of the accumulating solutes and makes no attempt to tackle the challenges involved in imposing constraints on metabolism related to insect resistance, texture and flavour, Nevertheless, introducing such constraints into the model might improve its ability to predict sucrose and organic acid levels.

Finally, the GrOE-FBA model predicts metabolic fluxes by flux optimization and does not account for signalling and regulation of metabolism, although these could be included in the form of 
experimental constraints on maximal enzyme activity. As a result, the model we present does not activate flux through energy dissipation mechanisms (such as alternative NADH dehydrogenases and alternative oxidase) and hence the GrOE-FBA model is unable to predict the respiratory climacteric (Colombié et al., 2017). A computationally expensive FBA approach called costweighted flux minimization has been shown to be capable of predicting alternative pathways in source leaves (Cheung et al., 2015). Such an approach might allow the multiphase GrOE-FBA tomato model to predict metabolically inefficient processes such as AOX flux and futile cycles.

\section{CONCLUSION}

GrOE-FBA, a novel FBA approach that uses volume-based osmotic constraints allows metabolism to be modelled during cell expansion, and thus extends the scope of constraints-based metabolic modelling to growing tissues in which expansion of existing cells is the dominant driver of growth. Understanding metabolism in expanding cells could help develop engineering strategies to optimize metabolism during the cell expansion phase of leaf and root development. The approach could also be used to study metabolism in guard cells where turgor-pressure-driven changes in cell size regulate stomatal aperture, in turn regulating $\mathrm{CO}_{2}$ assimilation and transpiration rates. GrOE-FBA could therefore help complement current kinetic models of guard cells (Hills et al., 2012) with a more holistic modelling approach. Recently, there has been increased interest in combining metabolic models with whole plant developmental models (Marshall-Colon et al., 2017). Growth of sink tissues in the metabolic component of many whole plant models is currently represented solely by the accumulation of biomass components. The introduction of GrOE-FBA-driven expanding cells could help improve the representation of metabolism in these models, potentially improving their predictive power.

\section{MATERIALS AND METHODS}

\section{Plant material and growth conditions}

Tomato (Solanum lycopersicum cv. "Moneymaker") seeds were sterilized and germinated on Murashige-Skoog (MS) medium. The plants were grown in a glasshouse in a $16 \mathrm{~h}$ photoperiod at 22 to $23^{\circ} \mathrm{C}$ day temperature and 20 to $22^{\circ} \mathrm{C}$ night temperature with supplementary lighting to maintain an irradiance of 250 to $400 \mu \mathrm{mol} \mathrm{m} \mathrm{m}^{-2} \mathrm{~s}^{-1}$. Lateral stems were systematically removed. Each flower anthesis was recorded, and trusses were pruned at five developed fruits to limit fruit size heterogeneity. Tomato fruits were harvested at nine different developmental stages corresponding to $8,15,22,28,34,42,50,52$ and 59 DPA with the last four corresponding to mature green, turning, orange and red fruit developmental stages respectively. Fruit samples

were collected from the first two levels of trusses in the plant. All materials were frozen in liquid nitrogen and storage at $-80^{\circ} \mathrm{C}$ until use.

\section{Fruit biomass measurements and morphology analysis}


Cell wall was extracted according to an established protocol (Ruprecht et al., 2011). The remaining insoluble material was washed with water and ethanol, air-dried and weighed. Lipids were extracted from a known mass of ground tissue using the chloroform/methanol protocol (Bligh and Dyer, 1959). Protein extracted with $6 \mathrm{M}$ urea, $2 \mathrm{M}$ thiourea buffer (Salem et al., 2016) was quantified using the Bradford assay (Bradford, 1976). The amino acid content of protein hydrolysates (50\% w/v trichloroacetic acid, $6 \mathrm{M} \mathrm{HCl}, 100^{\circ} \mathrm{C} / 24 \mathrm{~h}$ ) (Antoniewicz et al., 2007) was determined by an established GC/EI-TOF-MS protocol (Luedemann et al., 2008; Fernie et al., 2011; Osorio et al., 2011). Starch content was determined by enzymatic digestion and spectrophotometric assay of the resultant glucose (Hendriks et al., 2003). Fruit height and diameter were measured using a calibrated digital Vernier. The fresh weight to dry weight ratio (Fw/Dw) was determined by weighing fresh tissues and reweighing them after drying to constant weight in a forced-air oven at $65^{\circ} \mathrm{C}$.

\section{Harvesting phloem exudates}

Exudates were harvested from tissues corresponding to mature green and red fruit pedicels using the EDTA-facilitated method (Tetyuk et al., 2013).

\section{Gas-chromatography mass spectrometry of fruit content}

Metabolite analysis of fruit samples was performed using gas chromatography coupled to electron impact ionization-time of flight-mass spectrometry (GC/EI-TOF-MS) (Lisec et al., 2006). Plant material was extracted using the method described elsewhere (Osorio et al., 2011). Data analysis was performed using ChromaTOF 1.0 (Leco, www.leco.com) and TagFinder v.4.0 (Luedemann et al., 2008). Cross-referencing of mass spectra was performed with the Golm Metabolome database (Kopka et al., 2005). Documentation of metabolite profiling data acquisition is reported following recommended guidelines (Fernie et al., 2011). Curve fitting (Colombié et al., 2015) was used to generate curves for metabolite content and fluxes based on experimental measurements.

\section{Flux balance analysis and flux variability analysis}

Metabolic reactions associated with phospholipid biosynthesis (PC, PE and PA), amino acid catabolism, nucleotide biosynthesis, $\beta$ oxidation, lycopene biosynthesis and phytol metabolism were added to a previously published mass and charge-balanced model of primary metabolism in plant cells (Shameer et al., 2018) to generate the model PlantCoreMetabolism_v1_2. A complete log of all model curations and associated literature is presented in Table S2. Parsimonious FBA (pFBA) and FVA functions available in cobrapy (Ebrahim et al., 2013) version 0.13.4 were updated to perform weighted-pFBA and weighted-FVA, respectively. Aggregator reactions used to measure fruit metabolite content were given a zero weight while all other reactions were given a weight of 1 . Cobrapy in Jupyter notebook (python 2.7) was used to run and document all scripts (https://github.com/ljs1002/Shameer-et-al-Predicting-metabolism-duringgrowth-by-osmotic-cell-expansion). 


\section{Estimating maintenance costs}

Non-growth associated maintenance (NGAM) costs in all models were represented by flux through an ATPase and three NADPH oxidase (cytosolic, mitochondrial and plastidic) pseudoreactions, constrained to a 3:1 (ATP hydrolysis: NADPH oxidase) ratio based on the results of a previously published study (Cheung et al., 2013).

Dividing cells were assumed to have a carbon conversion efficiency (CCE) of $70 \%$ based on previously published data (Chen and Shachar-Hill, 2012). Fluxes through the NGAM reactions in the dividing cell model were gradually increased until a CCE $70 \%$ was achieved. When the NGAM ATPase flux was constrained to $0.062 \mathrm{mmol} / \mathrm{mL} /$ day, the CCE of the system was observed to be 69.92\%. This NGAM ATPase flux was then used to constrain maintenance in the dividing cell model. The same NGAM constraints were imposed on the expanding cell model.

Each phase of the multiphase GrOE-FBA model was 5.1 days long. The mean respiratory cost of NGAM based on data reported by Walker and Thornley (1977) was assumed to be $1.7 \mathrm{mmol}$ $\mathrm{CO}_{2}$ /fruit/day throughout fruit development. This is equivalent to $8.5 \mathrm{mmol} \mathrm{CO} /$ fruit/5.1 days. Using a model of primary metabolism in pericarp cell constrained so as to prevent the net synthesis of any metabolite, an NGAM ATPase flux of $26.2 \mathrm{mmol} /$ fruit/5.1 days was found to result in a respiration rate of $8.5 \mathrm{mmol} \mathrm{CO}_{2} /$ fruit/5.1 days. This NGAM ATPase flux was used to constrain NGAM in all phases of fruit development.

\section{Modelling primary metabolism in a dividing heterotrophic cell suspension}

The PlantCoreMetabolism_v1_2 model, was used to generate representations of metabolism in dividing tomato cells. Previously published data from tomato heterotrophic cell suspension cultures report a maximum growth rate of $2 \mathrm{mg} \mathrm{DW} / \mathrm{mL} /$ day (Rontein et al., 2002). Data on biomass content (cell wall, sugars, organic acids and protein) of cells demonstrating the maximum growth rate, from the same study, was used to generate a biomass equation for the dividing cell system as in conventional FBA modelling. The lipid: cellulose content ratio reported in Arabidopsis cell cultures (Williams et al., 2010) were used to estimate the lipid content of the cells and the biomass equation was updated accordingly. The biomass accumulation rate of the model was constrained to $2 \mathrm{mg} \mathrm{DW} / \mathrm{mL} /$ day. For the sake of simplification, the cell wall and cell membrane were assumed to be composed of only cellulose and phosphatidic acid (PA) respectively. Constraints based on equation 2 were introduced to promote solute partitioning between cytosol and vacuole. Because of the lack of data available in heterotrophic tomato cells, the value for $V_{v} / V_{c}$ required for equation 2 was calculated from data published on tomato pericarp subcellular volume fractions (Beauvoit et al., 2014). NGAM was represented in the model as described earlier. Glucose was set as the sole carbon source and FBA with minimization of sum of fluxes as the objective was used to predict the optimal flux distribution. 


\section{Modelling primary metabolism in a system of expanding 26 DPA pericarp cells}

The PlantCoreMetabolism_v1_2 model, was used to generate representations of metabolism in expanding 26 DPA tomato pericarp cells. The rate of cell expansion was estimated to be at its highest in 26 DPA tomato pericarp cells $(0.174 \mathrm{~nL} /$ cell/day; estimated from data in Beavuoit et al., 2014). For the sake of consistency, the number of cells in the expanding cell system was kept equal to that in the dividing cell suspension when growth rate attained the maximum rate of 2 $\mathrm{mg} \mathrm{DW} / \mathrm{mL} /$ day $\left(1.45 \times 10^{6}\right.$ cells $\left./ \mathrm{mL}\right)$. The composition of soluble metabolites in 26 DPA pericarp cells were estimated from third-degree polynomial curves fitted to published experimental data (Colombié et al., 2015). Equations 1 and 2 were used to introduce osmotic constraints in the model and the values for $V_{c e l l}$ and $C_{c e l l}$ were estimated from published data (Almeida and Huber, 1999; Beauvoit et al., 2014). The difference in osmotic content between DPA 26 and 27 was used to set the demand for osmolytes. Data on subcellular volume fractions published by Beauvoit et al. were used to calculate $V_{v} / V_{c}$ at 26 DPA. The difference between cellulose, lipid and protein content between DPA 26 and DPA 27, as calculated from equation 3 - 5, was used to set the demand for these biomass elements. NGAM was was represented in the model as described earlier. Glucose was set as the sole carbon source (as in the dividing-cells model) and FBA was used to predict metabolic fluxes that minimized the sum of fluxes while maximizing the organic content.

\section{Implementation of GrOE-FBA constraints in the multiphase developing fruit model}

Tomato fruit development from 13.1 to 43.7 DPA (mature green fruits observed at 42 DPA) is mainly due to expansion of existing cells (Gillaspy et al., 1993) and GrOE-FBA was used to model metabolism during these stages. Assuming the tomato fruit is composed of uniformly packed pericarp cells, equation 1 cam be transformed to the following form for a whole fruit,

$$
\sum n_{i} m_{i}=C_{\text {cell }} V_{\text {fruit }}
$$

where $i$ is a metabolite/ion in the fruit and $V_{\text {fruit }}$ is the volume of the fruit.

Constraints based on equation 2 and 6 were imposed on each phase of the multiphase developing fruit model. Previously published data on subcellular volume fractions (Beauvoit et al., 2014) were used to calculate $V_{v} / V_{c}$ during the different stages of fruit development and $C_{\text {cell }}$ was estimated based on osmolalities reported in the literature (Almeida and Huber, 1999). Values for $V_{\text {fruit }}$ for all 10 phases of fruit development modelled were determined experimentally (Table S1).

Pericarp cell volume for each phase of the multiphase fruit model was calculated from published data (Beauvoit et al., 2014), and cellulose, phospholipid and protein demand fluxes were imposed on the system using equations 3,4 and 5 and scaling them from $\mu \mathrm{mol} /$ cell to $\mathrm{mmol} /$ fruit. 
Carbon influx rate into developing tomato fruits has been reported to be inversely proportional to fruit carbon content and size (Walker and Ho, 1977a,b). A hyperbolic curve was fitted to capture the relationship between carbon influx rates and fruit carbon content more accurately. Fruit carbon content has been reported to be linearly related to fruit volume (Walker and Ho, 1997b). Hence, initial carbon content for each developmental phase was calculated based on fruit volume at the respective phases. These values were then used to predict the upper bounds for the flux of nutrients from the phloem in the respective phases of the developing tomato model.

\section{REFERENCES}

Almeida, D.P.F. and Huber, D.J. (1999) Apoplastic pH and inorganic ion levels in tomato fruit: A potential means for regulation of cell wall metabolism during ripening. Physiol. Plant. 105, 506-512. https://doi.org/10.1034/j.13993054.1999.105316.x

Antoniewicz, M.R., Kelleher, J.K. and Stephanopoulos, G. (2007) Accurate assessment of amino acid mass isotopomer distributions for metabolic flux analysis. Anal. Chem. 79, 7554-7559. http://doi.org/10.1021/ac0708893

Beauvoit, B.P., Colombié, S., Monier, A., Andrieu, M.-H., Biais, B., Bénard, C., Chéniclet, C., Dieuaide-Noubhani, M., Nazaret, C., Mazat, J.-P. and Gibon, Y. (2014) Model-assisted analysis of sugar metabolism throughout tomato fruit development reveals enzyme and carrier properties in relation to vacuole expansion. Plant Cell 26, 3224-3242. http://doi.org/10.1105/tpc.114.127761

Biais, B., Bénard, C., Beauvoit, B., Colombié, S., Prodhomme, D., Ménard, G., Bernillon, S., Gehl, B., Gautier, H., Ballias, P., Mazat, J.-P., Sweetlove, L., Génard, M. and Gibon, Y. (2014) Remarkable reproducibility of enzyme activity profiles in tomato fruits grown under contrasting environments provides a roadmap for studies of fruit metabolism. Plant Physiol. 164, 12041221. http://doi.org/10.1104/pp.113.231241

Bligh, E.G. and Dyer, W.J. (1959) A rapid method of total lipid extraction and purification. Can. J. Biochem. Physiol. 37, 911-917. https://doi.org/10.1139/059-099

Boyer, J.S., Cavalieri, A.J. and Schulze, E.-D. (1985) Control of the rate of cell enlargement: Excision, wall relaxation, and growth-induced water potentials. Planta 163, 527-543. https://doi.org/10.1007/BF00392710 
Bradford, M.M. (1976) A rapid and sensitive method for the quantitation of microgram quantities of protein utilizing the principle of protein-dye binding. Anal. Biochem. 72, 248-254. https://doi.org/10.1016/0003-2697(76)90527-3

Cacas, J.-L., Buré, C., Grosjean, K., Gerbeau-Pissot, P., Lherminier, J., Rombouts, Y., Maes, E., Bossard, C., Gronnier, J., Furt, F., Fouillen, L., Germain, V., Bayer, E., Cluzet, S., Robert, F., Schmitter, J.-M., Deleu, M., Lins, L., SimonPlas, F. and Mongrand, S. (2016) Revisiting plant plasma membrane lipids in tobacco: A focus on sphingolipids. Plant Physiol. 170, 367-384. https://doi.org/10.1104/pp.15.00564

Carrari, F., Baxter, C., Usadel, B., Urbanczyk-Wochniak, E., Zanor, M.-I., NunesNesi, A., Nikiforova, V., Centero, D., Ratzka, A., Pauly, M., Sweetlove, L.J. and Fernie, A.R. (2006) Integrated analysis of metabolite and transcript levels reveals the metabolic shifts that underlie tomato fruit development and highlight regulatory aspects of metabolic network behavior. Plant Physiol. 142, 1380-1396. http://doi.org/10.1104/pp.106.088534

Carrari, F. and Fernie, A.R. (2006) Metabolic regulation underlying tomato fruit development. J. Exp. Bot. 57, 1883-1897. https://doi.org/10.1093/jxb/erj020

Chen, X. and Shachar-Hill, Y. (2012) Insights into metabolic efficiency from flux analysis. J. Exp. Bot. 63, 2343-2351. http://doi.org/10.1093/jxb/ers057

Cheung, C.Y.M., Poolman, M.G., Fell, D.A., Ratcliffe, R.G. and Sweetlove, L.J. (2014) A diel flux balance model captures interactions between light and dark metabolism during day-night cycles in $\mathrm{C}_{3}$ and crassulacean acid metabolism leaves. Plant Physiol. 165, 917-929. https://doi.org/10.1104/pp.113.234468

Cheung, C.Y.M., Ratcliffe, R.G. and Sweetlove, L.J. (2015) A method of accounting for enzyme costs in flux balance analysis reveals alternative pathways and metabolite stores in an illuminated Arabidopsis leaf. Plant Physiol. 169, 1671-1682. https://doi.org/10.1104/pp.15.00880

Cheung, C.Y.M., Williams, T.C.R., Poolman, M.G., Fell, D.A., Ratcliffe, R.G. and Sweetlove, L.J. (2013) A method for accounting for maintenance costs in flux balance analysis improves the prediction of plant cell metabolic phenotypes under stress conditions. Plant J. 75, 1050-1061. https://doi.org/10.1111/tpj.12252

Cohen, S., Itkin, M., Yeselson, Y., Tzuri, G., Portnoy, V., Harel-Baja, R., Lev, S., Sa'ar, U., Davidovitz-Rikanati, R., Baranes, N., Bar, E., Wolf, D., Petreikov, 
M., Shen, S., Ben-Dor, S., Rogachev, I., Aharoni, A., Ast, T., Schuldiner, M., Belausov, E., Eshed, R., Ophir, R., Sherman, A., Frei, B., Neuhaus, H.E., Xu, Y., Fei, Z., Giovannoni, J., Lewinsohn, E., Tadmor, Y., Paris, H.S., Katzir, N., Burger, Y. and Schaffer, A.A. (2014) The PH gene determines fruit acidity and contributes to the evolution of sweet melons. Nat. Commun. 5, 4026. http://doi.org/10.1038/ncomms5026

Colombié, S., Beauvoit, B., Nazaret, C., Bénard, C., Vercambre, G., Gall, S. Le, Biais, B., Cabasson, C., Maucourt, M., Bernillon, S., Moing, A., DieuaideNoubhani, M., Mazat, J.P. and Gibon, Y. (2017) Respiration climacteric in tomato fruits elucidated by constraint-based modelling. New Phytol. 213, 1726-1739. http://doi.org/10.1111/nph.14301

Colombié, S., Nazaret, C., Bénard, C., Biais, B., Mengin, V., Solé, M., Fouillen, L., Dieuaide-Noubhani, M., Mazat, J.-P., Beauvoit, B. and Gibon, Y. (2015) Modelling central metabolic fluxes by constraint-based optimization reveals metabolic reprogramming of developing Solanum lycopersicum (tomato) fruit. Plant J. 81, 24-39. https://doi.org/10.1111/tpj.12685

de Oliveira Dal'Molin, C.G. de and Nielsen, L.K. (2018) Plant genome-scale reconstruction: from single cell to multi-tissue modelling and omics analyses. Curr. Opin. Biotechnol. 49, 42-48. http://doi.org/10.1016/j.copbio.2017.07.009

de Oliveira Dal'Molin, C.G. de, Quek, L.-E., Saa, P.A. and Nielsen, L.K. (2015) A multi-tissue genome-scale metabolic modeling framework for the analysis of whole plant systems. Front. Plant Sci. 6, 4. https://doi.org/10.3389/fpls.2015.00004

Ebrahim, A., Lerman, J.A., Palsson, B.O. and Hyduke, D.R. (2013) COBRApy: constraints-based reconstruction and analysis for python. BMC Syst. Biol. 7, 74. https://doi.org/10.1186/1752-0509-7-74

Fahlgren, N., Gehan, M.A. and Baxter, I. (2015) Lights, camera, action: highthroughput plant phenotyping is ready for a close-up. Curr. Opin. Plant Biol. 24, 93-99. https://doi.org/10.1016/j.pbi.2015.02.006

Feist, A.M., Henry, C.S., Reed, J.L., Krummenacker, M., Joyce, A.R., Karp, P.D., Broadbelt, L.J., Hatzimanikatis, V. and Palsson, B. $\varnothing$. (2007) A genome-scale metabolic reconstruction for Escherichia coli K-12 MG1655 that accounts for 1260 ORFs and thermodynamic information. Mol. Syst. Biol. 3, 121. 
http://doi.org/10.1038/msb4100155

Feist, A.M. and Palsson, B.O. (2010) The biomass objective function. Curr. Opin. Microbiol. 13, 344-349. https://doi.org/10.1016/j.mib.2010.03.003

Fernie, A.R., Aharoni, A., Willmitzer, L., Stitt, M., Tohge, T., Kopka, J., Carroll, A.J., Saito, K., Fraser, P.D. and DeLuca, V. (2011) Recommendations for reporting metabolite data. Plant Cell 23, 2477-2482. http://doi.org/10.1105/tpc.111.086272

Gillaspy, G., Ben-David, H. and Gruissem, W. (1993) Fruits: A developmental perspective. Plant Cell 5, 1439-1451. https://doi.org/10.1105/tpc.5.10.1439

Gonzalez, N., Vanhaeren, H. and Inzé, D. (2012) Leaf size control: Complex coordination of cell division and expansion. Trends Plant Sci. 17, 332-340. http://doi.org/10.1016/j.tplants.2012.02.003

Grafahrend-Belau, E., Junker, A., Eschenroder, A., Muller, J., Schreiber, F. and Junker, B.H. (2013) Multiscale metabolic modeling: Dynamic flux balance analysis on a whole-plant scale. Plant Physiol. 163, 637-647. https://doi.org/10.1104/pp.113.224006

Guclu, J., Paulin, A. and Soudain, P. (1989) Changes in polar lipids during ripening and senescence of cherry tomato (Lycopersicon esculentum): Relation to climacteric and ethylene increases. Physiol. Plant. 77, 413-419. https://doi.org/10.1111/j.1399-3054.1989.tb05662.x

Hendriks, J.H.M., Kolbe, A., Gibon, Y., Stitt, M. and Geigenberger, P. (2003) ADPglucose pyrophosphorylase is activated by posttranslational redoxmodification in response to light and to sugars in leaves of Arabidopsis and other plant species. Plant Physiol. 133, 838-849. https://doi.org/10.1104/pp.103.024513

Hills, A., Chen, Z.-H., Amtmann, A., Blatt, M.R. and Lew, V.L. (2012) OnGuard, a computational platform for quantitative kinetic modeling of guard cell physiology. Plant Physiol. 159, 1026-1042. https://doi.org/10.1104/pp.112.197244

Ho, L.C. and Hewitt, J.D. (1986) Fruit development. In The Tomato Crop A scientific basis for improvement (Antherton, J. and Rudich, J., eds). London: Chapman and Hall, pp. 201-240. http://doi.org/10.1007/978-94-009-3137-4

Kopka, J., Schauer, N., Krueger, S., Birkemeyer, C., Usadel, B., Bergmüller, E., 
Dörmann, P., Weckwerth, W., Gibon, Y., Stitt, M., Willmitzer, L., Fernie, A.R. and Steinhauser, D. (2005) GMD@CSB.DB: The Golm metabolome database. Bioinformatics 21, 1635-1638. https://doi.org/10.1093/bioinformatics/bti236

Kruger, N.J., Lay, P. Le and Ratcliffe, R.G. (2007) Vacuolar compartmentation complicates the steady-state analysis of glucose metabolism and forces reappraisal of sucrose cycling in plants. Phytochemistry 68, 2189-2196. https://doi.org/10.1016/j.phytochem.2007.04.004

Legland, D., Devaux, M.F., Bouchet, B., Guillon, F. and Lahaye, M. (2012) Cartography of cell morphology in tomato pericarp at the fruit scale. J. Microsc. 247, 78-93. http://doi.org/10.1111/j.1365-2818.2012.03623.x

Lisec, J., Schauer, N., Kopka, J., Willmitzer, L. and Fernie, A.R. (2006) Gas chromatography mass spectrometry-based metabolite profiling in plants. Nat. Protoc. 1, 387-396. https://doi.org/10.1038/nprot.2006.59Luedemann, A., Strassburg, K., Erban, A. and Kopka, J. (2008) TagFinder for the quantitative analysis of gas chromatography - mass spectrometry (GC-MS)-based metabolite profiling experiments. Bioinformatics 24, 732-737. http://doi.org/10.1093/bioinformatics/btn023

Lynch, J.P. (2019) Root phenotypes for improved nutrient capture: an underexploited opportunity for global agriculture. New Phytol. 223, 548-564. https://doi.org/10.1111/nph.15738

Marshall-Colon, A., Long, S.P., Allen, D.K., Allen, G., Beard, D.A., Benes, B., Caemmerer, S. von, Christensen, A.J., Cox, D.J., Hart, J.C., Hirst, P.M., Kannan, K., Katz, D.S., Lynch, J.P., Millar, A.J., Panneerselvam, B., Price, N.D., Prusinkiewicz, P., Raila, D., Shekar, R.G., Shrivastava, S., Shukla, D., Srinivasan, V., Stitt, M., Turk, M.J., Voit, E.O., Wang, Y., Yin, X. and Zhu, X.G. (2017) Crops In Silico: Generating virtual crops using an integrative and multi-scale modeling platform. Front. Plant Sci. 8, 786. https://doi.org/10.3389/fpls.2017.00786

Nikoloski, Z., Perez-Storey, R. and Sweetlove, L.J. (2015) Inference and prediction of metabolic network fluxes. Plant Physiol. 169, 1443-1455. http://doi.org/10.1104/pp.15.01082

Osorio, S., Do, P.T. and Fernie, A.R. (2011) Profiling primary metabolites of tomato fruit with gas chromatography/mass spectrometry. In Plant Metabolomics. Methods in Molecular Biology (Methods and Protocols) 
(Hardy, N. W. and Hall, R. D., eds.). Humana Press, pp. 101-109.

Petreikov, M., Shen, S., Yeselson, Y., Levin, I., Bar, M. and Schaffer, A.A. (2006) Temporally extended gene expression of the ADP-Glc pyrophosphorylase large subunit (AgpL1) leads to increased enzyme activity in developing tomato fruit. Planta 224, 1465-1479. https://doi.org/10.1007/s00425-006-0316-y

Petreikov, M., Yeselson, L., Shen, S., Levin, I., Schaffer, A.A., Dagan, B., Efrati, A., Bar, M. and Co, G.S. (2009) Carbohydrate balance and accumulation during development of near-isogenic tomato lines differing in the AGPase-L1 allele. J. Am. Soc. Hortic. Sci. 134, 134-140. https://doi.org/10.21273/JASHS.134.1.134

Rolin, D., Baldet, P., Just, D., Chevalier, C., Biran, M. and Raymond, P. (2000) NMR study of low subcellular $\mathrm{pH}$ during the development of cherry tomato fruit. Aust. J. Plant Physiol. 27, 61-69. https://doi.org/10.1071/PP99051

Rontein, D., Dieuaide-Noubhani, M., Dufourc, E.J., Raymond, P. and Rolin, D. (2002) The metabolic architecture of plant cells. J. Biol. Chem. 277, 4394843960. doi: 10.1074/jbc.M206366200

Ruprecht, C., Mutwil, M., Saxe, F., Eder, M., Nikoloski, Z. and Persson, S. (2011) Large-scale co-expression approach to dissect secondary cell wall formation across plant species. Front. Plant Sci. 2, 23. http://doi.org/10.3389/fpls.2011.00023

Salem, M.A., Jüppner, J., Bajdzienko, K. and Giavalisco, P. (2016) Protocol: a fast, comprehensive and reproducible one-step extraction method for the rapid preparation of polar and semi-polar metabolites, lipids, proteins, starch and cell wall polymers from a single sample. Plant Methods 12, 45. https://doi.org/10.1186/s13007-016-0146-2

Scheunemann, M., Brady, S.M. and Nikoloski, Z. (2018) Integration of large-scale data for extraction of integrated Arabidopsis root cell-type specific models. Sci. Rep. 8, 7919. https://doi.org/10.1038/s41598-018-26232-8

Schwender, J. and Hay, J.O. (2012) Predictive modeling of biomass component tradeoffs in brassica napus developing oilseeds based on in silico manipulation of storage metabolism. Plant Physiol. 160, 1218-1236. https://doi.org/10.1104/pp.112.203927

Shameer, S., Baghalian, K., Cheung, C.Y.M., Ratcliffe, R.G. and Sweetlove, L.J. (2018) Computational analysis of the productivity potential of CAM. Nat. 
Plants 4, 165-171. http://doi.org/10.1038/s41477-018-0112-2

Shaw, R. and Cheung, C.Y.M. (2018) A dynamic multi-tissue flux balance model captures carbon and nitrogen metabolism and optimal resource partitioning during Arabidopsis growth. Front. Plant Sci. 9, 884. https://doi.org/10.3389/fpls.2018.00884Sweetlove, L.J. and Ratcliffe, R.G. (2011) Flux-balance modeling of plant metabolism. Front. Plant Sci. 2, 38. https://doi.org/10.3389/fpls.2011.00038

Taiz (1992) The plant vacuole. J. Exp. Biol. 172, 113-122.

Takayama, M. and Ezura, H. (2015) How and why does tomato accumulate a large amount of GABA in the fruit? Front. Plant Sci. 6, 612. https://doi.org/10.3389/fpls.2015.00612

Tardieu, F., Cabrera-Bosquet, L., Pridmore, T. and Bennett, M. (2017) Plant phenomics, from sensors to knowledge. Curr. Biol. 27, R770-R783. https://doi.org/10.1016/j.cub.2017.05.055

Tetyuk, O., Benning, U.F. and Hoffmann-Benning, S. (2013) Collection and analysis of Arabidopsis phloem exudates using the EDTA-facilitated method. J. Vis. Exp., e51111. http://doi.org/10.3791/51111

Tohge, T., Alseekh, S. and Fernie, A.R. (2014) On the regulation and function of secondary metabolism during fruit development and ripening. J. Exp. Bot. 65, 4599-4611. https://doi.org/10.1093/jxb/ert443

Valle, E.M., Boggio, S.B. and Heldt, H.W. (1998) Free amino acid composition of phloem sap and growing fruit of Lycopersicon esculentum. Plant Cell Physiol. 39, 458-461.

Varma, A. and Palsson, B.O. (1994) Stoichiometric flux balance models quantitatively predict growth and metabolic by-product secretion in wild-type Escherichia coli W3110. Appl. Environ. Microbiol. 60, 3724-3731.

Walker, A.J. and Ho, L.C. (1977a) Carbon translocation in the tomato: carbon import and fruit growth. Ann. Bot. 41, 813-823.

Walker, A.J. and Ho, L.C. (1977b) Carbon translocation in the tomato: effects of fruit temperature on carbon metabolism and the rate of translocation. Ann. Bot 41, 825-832.

Williams, T.C.R., Poolman, M.G., Howden, A.J.M., Schwarzlander, M., Fell, D.A., 
Ratcliffe, R.G. and Sweetlove, L.J. (2010) A genome-scale metabolic model accurately predicts fluxes in central carbon metabolism under stress conditions. Plant Physiol. 154, 311-323. http://doi.org/10.1104/pp.110.158535

Yuan, H., Cheung, C.Y.M., Poolman, M.G., Hilbers, P.A.J. and Riel, N.A.W. van (2016) A genome-scale metabolic network reconstruction of tomato (Solanum lycopersicum L.) and its application to photorespiratory metabolism. Plant J. 85, 289-304. https://doi.org/10.1111/tpj.13075 